${ }^{1}$ Department of Infectious Diseases and Immunology, Children's Hospital, University of Munich, Munich, Germany; ${ }^{2}$ Department of Internal Medicine, Innsbruck Medical University, Innsbruck, Austria; ${ }^{3}$ General Hospital of the Elisabethinen, Klagenfurt, Austria; ${ }^{4}$ Department of Clinical Chemistry - Grosshadern, University of Munich, Munich, Germany

\section{Correspondence to:} Dr S Stojanov, Genetics and Genomics Branch, National Institute of Arthritis and Musculoskeletal and Skin Diseases, National Institutes of Health, Building 10, Room 9N210, 10 Center Drive, Bethesda, MD 20892, USA; stojanos@mail.nih.gov

SS and CD contributed equally to this work.

Accepted 20 December 2007 Published Online First

7 January 2008

\title{
Clinical and functional characterisation of a novel TNFRSF1A c.605T >A/V173D cleavage site mutation associated with tumour necrosis factor receptor- associated periodic fever syndrome (TRAPS), cardiovascular complications and excellent response to etanercept treatment
}

\author{
S Stojanov, ${ }^{1}$ C Dejaco, ${ }^{2,3}$ P Lohse, ${ }^{4} \mathrm{~K} \mathrm{Huss}{ }^{1}$ C Duftner ${ }^{2,3}$ B H Belohradsky, ${ }^{1}$ M Herold ${ }^{2}$ \\ M Schirmer ${ }^{2,3}$
}

\begin{abstract}
Objectives: To study the clinical outcome, treatment response, T-cell subsets and functional consequences of a novel tumour necrosis factor (TNF) receptor type 1 (TNFRSF1A) mutation affecting the receptor cleavage site.
\end{abstract}

Methods: Patients with symptoms suggestive of tumour necrosis factor receptor-associated periodic syndrome (TRAPS) and 22 healthy controls (HC) were screened for mutations in the TNFRSF1A gene. Soluble TNFRSF1A and inflammatory cytokines were measured by ELISAs. TNFRSF1A shedding was examined by stimulation of peripheral blood mononuclear cells (PBMCs) with phorbol 12-myristate 13-acetate followed by flow cytometric analysis (FACS). Apoptosis of PBMCs was studied by stimulation with TNF $\alpha$ in the presence of cycloheximide and annexin $\mathrm{V}$ staining. T cell phenotypes were monitored by FACS.

Results: TNFRSF1A sequencing disclosed a novel V173D/ p.Val202Asp substitution encoded by exon 6 in one family, the c.194-14G>A splice variant in another and the R920/p.Arg121GIn substitution in two families. Cardiovascular complications (lethal heart attack and peripheral arterial thrombosis) developed in two V173D patients. Subsequent etanercept treatment of the V173D carriers was highly effective over an 18-month follow-up period. Serum TNFRSF1A levels did not differ between TRAPS patients and HC, while TNFRSF1A cleavage from monocytes was significantly reduced in V173D and R920 patients. TNF $\alpha$-induced apoptosis of PBMCs and T-cell senescence were comparable between V173D patients and $\mathrm{HC}$.

Conclusions: The TNFRSF1A V173D cleavage site mutation may be associated with an increased risk for cardiovascular complications and shows a strong response to etanercept. T-cell senescence does not seem to have a pathogenetic role in affected patients.

Hereditary autoinflammatory syndromes are characterised by recurrent multisystemic inflammation with increased acute phase reactants, but absent infection, high-titre autoantibodies or antigenspecific $\mathrm{T}$ lymphocytes (reviewed by Stojanov and Kastner ${ }^{1}$ ). The tumour necrosis factor receptor-associated periodic syndrome (TRAPS; Mendelian inheritance in man no 142680) is the most common autosomal dominantly inherited autoinflammatory syndrome affecting patients of diverse ethnicities. ${ }^{2}$ Characteristic clinical features are recurrent and prolonged ( $>5$ days) episodes of fever in conjunction with severe abdominal pain, centrifugally migrating localised myalgia with associated painful erythematous skin rash as well as conjunctivitis and unilateral periorbital oedema. $^{34}$

TRAPS is caused by sequence alterations in the TNFRSF1A gene on chromosome 12p13, which encodes the ubiquitously expressed $55 \mathrm{kDa}$ TNF receptor (TNFRSF1A, CD120a). ${ }^{2}$ More than 50 TRAPS-related mutations have been reported so far (INFEVERS database at http://fmf.igh.cnrs.fr/infevers (accessed 29 May 2008) ${ }^{5}$ ). The majority are single nucleotide missense mutations within TNFRSF1A exons 2, 3 and 4, affecting the first three of four extracellular cysteine-rich domains of the receptor. $\mathrm{R} 92 \mathrm{O}$, a TNFRSF1A variant encoded by exon 4 , is found in $1-2.5 \%$ of the normal population and presents with an incomplete penetrance and milder or TRAPS-atypical clinical features. ${ }^{6-9}$ To date, only two mutations have been reported in exon 6: (a) $1170 \mathrm{~N} / \mathrm{p} . \mathrm{Il} 1 \mathrm{199Asn},{ }^{10}$ an amino acid substitution very close to the TNFRSF1A cleavage site (between p.Asn201 and p.Val202), which is adjacent to the transmembrane domain of TNFRSF1A ${ }^{11} 12$ and (b) L167_G175del/ p.Leu196_Gly204del, ${ }^{9}$ the first large in-frame interstitial deletion.

The TRAPS episodes were initially considered to be the consequence of a diminished antagonistic effect of soluble TNF receptors owing to an impaired activation-induced receptor cleavage (shedding), leading to an increase of unbound TNF $\alpha$ in the circulation. ${ }^{2}$ However, affected members of the first thoroughly described TRAPS family showed raised levels of interleukin 6 (IL6) and IL8, but not of TNF $\alpha,{ }^{13}{ }^{14}$ suggesting additional pathogenetic mechanisms. Recent experiments have shown a more complex situation with mutation- and cell type-dependent TNF receptor cleavage defects, ${ }^{15}$ TNF-independent NF- $\kappa B$ activation $^{16}$ and impairment of intracellular TNF receptor trafficking, TNF binding ${ }^{17}$ and TNF-induced apoptosis, ${ }^{918}$ probably caused by misfolding of the 
A

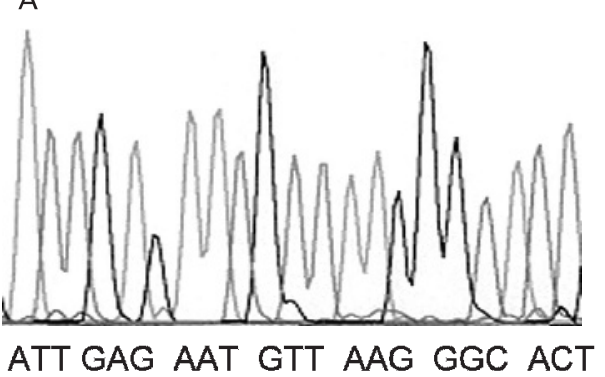

Ile

Glu Asn Val Lys Gly Thr

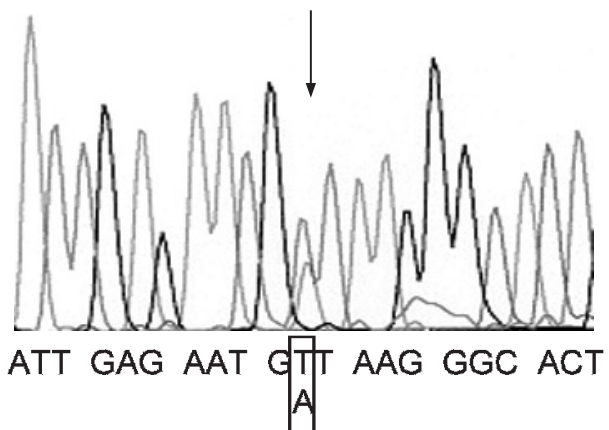

Ile Glu Asn Val/ Lys Gly Thr

B

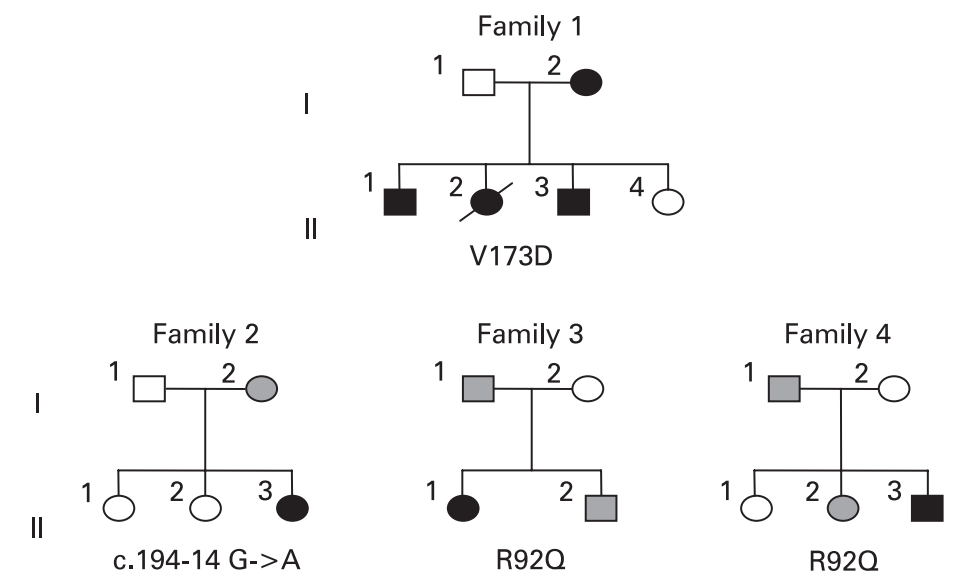

Figure 1 New TNFRSF1A cleavage site mutation V173D and pedigrees of the TRAPS families investigated. (A) Partial TNFRSF1A exon 6 sequence of a normal subject (left panel) and of a heterozygous mutation carrier (right panel). The arrow indicates the position of the $T \rightarrow A$ nucleotide substitution, resulting in a valine (GTT)-to-aspartic acid (GAT) exchange at amino acid position 173 of the mature protein. (B) Pedigrees of the four families with tumour necrosis factor receptor-associated periodic fever syndrome (TRAPS) caused by three different TNFRSF1A mutations, c.605T $>$ ANV173D, c.194-14G $>$ A and c.362G $>A$ /R920. Open symbols represent healthy subjects, solid symbols affected subjects and grey symbols healthy carriers.

extracellular domain of TNFRSF1A and leading to retention of the mutated receptors in the endoplasmic reticulum. ${ }^{19}$

The prognosis of TRAPS is mainly dependent on the development of systemic AA amyloidosis, which occurs in up to $14 \%$ of mutation-positive patients and asymptomatic carriers, $^{3}$ therefore warranting an efficient treatment. Although corticosteroids can be quite effective in more severe episodes, patients often require escalating doses, with subsequent side effects. Lately, etanercept, a TNF $\alpha$-neutralising agent, has been shown to elicit a beneficial therapeutic response in many patients (reviewed by Stojanov and McDermott ${ }^{4}$ ).

Here, we report a new TNFRSF1A mutation at the receptor cleavage site in an Austrian family. Two of the four affected members presented with cardiovascular complications. The V173D mutation was characterised by receptor shedding in comparison with two other TNRSF1A mutations and the treatment effect of etanercept was studied. The question of $\mathrm{T}$-cell senescence in TRAPS patients was also examined.

\section{PATIENTS AND METHODS}

\section{Study participants}

We included the members of four families carrying one of three different TRAPS-causing TNFRSF1A mutations, one of which was a novel mutation affecting the receptor cleavage site. One family was of Austrian, two of German and one of German/ Spanish ancestry. The probands or their parents, or both, were asked about their clinical symptoms and disease history.
A family history was present in one affected family. Blood was taken from all family members and also from 22 healthy Caucasian subjects, who served as normal controls. The study was approved by the ethics committee of the Innsbruck Medical University, Austria. Written informed consent was obtained from all participants or their parents before enrolment.

DNA extraction and sequence analysis of the TNFRSF1A, MVK, MEFV and NLRP3/CIAS1 genes

EDTA blood samples were collected from all participants and genomic DNA was extracted from white blood cells using the OIAamp blood mini-kit (Qiagen, Hilden, Germany). After amplification by PCR, TNFRSF1A exons 2, 3, 4 and 6 were sequenced. $M V K$ exons 9 and 11, MEFV exons 2 and 10 and NLRP3/CIAS1 exon 3 were also analysed in order to exclude common mutations resulting in other hereditary autoinflammatory fever syndromes. ${ }^{20} 21$

\section{Determination of soluble TNF receptors in serum and culture supernatants}

Soluble tumour necrosis factor receptor superfamily $1 \mathrm{~A}$ (sTNFRSF1A) and 1B (sTNFRSF1B) were measured in serum samples obtained from TNFRSF1A mutation-positive family members between attacks and from healthy controls (HC) as well as in culture supernatants of stimulated peripheral blood mononuclear cells (PBMCs) using ELISA kits (Bender MedSystems, Vienna, Austria) according to the manufacturer's 
Table 1 Clinical and laboratory characteristics of TNFRSF1A mutation-positive family members

\begin{tabular}{|c|c|c|c|c|c|c|c|c|c|c|c|c|}
\hline \multirow[b]{2}{*}{ Characteristics } & \multicolumn{12}{|c|}{ Family member } \\
\hline & $1-1.2$ & 1-II.1 & $1-I I .2$ & 1-II.3 & $2-1.2$ & $2-11.3$ & 3-I.1 & 3-II.1 & $3-1 I .2$ & 4-I.1 & $4-11.2$ & $4-1 I .3$ \\
\hline Ethnicity & Austrian & Austrian & Austrian & Austrian & German & German & German & German/Spanish & German/Spanish & German & German & German \\
\hline Gender & $\mathrm{F}$ & $\mathrm{M}$ & $\mathrm{F}$ & M & $\mathrm{F}$ & $\mathrm{F}$ & $\mathrm{M}$ & $\mathrm{F}$ & $\mathrm{M}$ & $\mathrm{M}$ & $\mathrm{F}$ & $\mathrm{M}$ \\
\hline Age (years) & 46 & 26 & Deceased & 23 & 57 & 15 & 44 & 8 & 5 & 53 & 21 & 12 \\
\hline $\begin{array}{l}\text { Age at disease } \\
\text { onset (years) }\end{array}$ & 6 & 1 & 6 & 5 & - & 12 & - & 3 & - & - & - & 10 \\
\hline Duration of fever (days) & $4-5$ & $3-7$ & 7 & 3 & - & $1-7$ & - & $1-5$ & - & - & - & $28-56$ \\
\hline Vomiting & + & - & + & + & - & - & - & + & - & - & - & - \\
\hline Hepatomegaly & - & - & - & + & - & - & - & - & - & - & - & - \\
\hline Myalgia & + & - & + & - & - & - & - & - & - & - & - & + \\
\hline Rash & + & ++ & + & + & - & - & - & - & - & - & - & + \\
\hline Conjunctivitis & - & - & - & - & - & - & - & - & - & - & - & + \\
\hline Lymphadenopathy & - & + & - & - & - & + & - & - & - & - & - & - \\
\hline Amyloidosis & - & - & - & - & - & - & - & Mild proteinuria & - & - & - & - \\
\hline $\begin{array}{l}\text { Mutation in the TNFRSF1A } \\
\text { gene }\end{array}$ & V173D & V173D & V173D & V173D & $\begin{array}{l}\text { c. } 194- \\
14 G>A\end{array}$ & $\begin{array}{l}\text { c. } 194- \\
14 G>A\end{array}$ & R920 & R920 & R920 & R920 & R920 & R920 \\
\hline Leucocytes $\times 10^{9} / \mathrm{I}$ & $8.8 \dagger$ & Normal $^{*} \dagger$ & $11.2^{*}$ & $3.8^{*}, 8.6 \dagger$ & Normal & $5.1 \dagger$ & NA & $11.5^{*}, 7.1 \dagger$ & 8.2 & NA & NA & $5.8 \dagger$ \\
\hline $\mathrm{CRP}(\mathrm{mg} / \mathrm{l})$ & $27 \dagger$ & $590^{*}, 121 \dagger$ & $381 \ddagger$ & $269^{*}$, normal $\uparrow$ & Normal & $0.5 \dagger$ & NA & $38^{*},<0.5 \dagger$ & $<0.5$ & NA & NA & $<0.5 \dagger$ \\
\hline SAA (mg/l) & ND & $773^{*}$ & ND & ND & NA & $110^{*},<0.7 \dagger$ & NA & $220^{*}, 2.3 \dagger$ & 1.4 & NA & NA & $5.2 \uparrow$ \\
\hline $\mathrm{ESR}(\mathrm{mm} / 1 \mathrm{st} \mathrm{h})$ & $60 \dagger$ & $90^{*}, 72 \dagger$ & ND & $105^{*}, 16 \dagger$ & NA & $7 \dagger$ & NA & $19 *$ & 6 & NA & NA & $6 \dagger$ \\
\hline Fibrinogen $(\mathrm{g} / \mathrm{l})$ & $5.50 \dagger$ & $8.85 \dagger$ & $\begin{array}{l}10.0^{*} \\
4.32 \dagger\end{array}$ & $10.59 *$ & NA & ND & NA & ND & ND & NA & NA & ND \\
\hline
\end{tabular}

*Highest documented value measured during an attack; †highest documented value measured between attacks.

CRP, C-reactive protein (normal $<5 \mathrm{mg} /$ ); ESR, erythrocyte sedimentation rate (normal $<10 \mathrm{~mm} / 1 \mathrm{st} \mathrm{h}$ ); NA, not available; ND, not determined; SAA, serum amyloid A (normal $<5 \mathrm{mg} / \mathrm{l}) ;++$, severe; + , present; - , absent.

instructions. The detection limits of the assays were $<53 \mathrm{pg} / \mathrm{ml}$ for sTNFRSF1A and $<99 \mathrm{pg} / \mathrm{ml}$ for sTNFRSF1B. Samples from patients (but not from controls) were analysed in duplicate and the mean of the two values was calculated. Investigators were blinded to the identity of all samples.

\section{Cell activation and flow cytometric analysis}

To study cleavage of the extracellular domain of TNFRSF1A, PBMCs were isolated from patients with TRAPS and from HC as previously described. ${ }^{22}$ Assays using PBMCs from healthy and affected family members were performed in parallel and investigators were unaware of the results of the TNFRSF1A mutation analysis. Data from healthy family members were allocated to the HC group.

PBMCs were stimulated with phorbol 12-myristate 13acetate (PMA; Sigma, Munich, Germany) for $25 \mathrm{~min}$ at $37^{\circ} \mathrm{C}$. The optimal concentration of PMA was critical for performance of the shedding assays. In a preliminary study, concentrations ranging from 1 to $20 \mathrm{ng} / \mathrm{ml}$ induced optimal shedding in $\mathrm{HC}$ without destroying cells. After washing, cells were stained for $30 \mathrm{~min}$ at $4^{\circ} \mathrm{C}$ with fluorescein isothiocyanate (FITC)-conjugated anti-CD120a (TNFRSF1A) monoclonal antibody (mAb) and peridinin chlorophyll protein-conjugated anti-CD14 (monocytes) and anti-CD3 (T cells) (Becton Dickinson, San Diego, California, USA). ${ }^{23}$ Corresponding isotype control antibodies were used.

For T-cell subtype analysis, freshly isolated PBMCs were stained with FITC-conjugated mAbs (CD4, CD25, CD28 and CD45RA), phycoerythrin-conjugated mAbs (CD28 and
CD45RO) and peridinin chlorophyll protein-conjugated mAbs (CD3, CD4 or CD8), as appropriate.

Stained cells were analysed on a FACS-Calibur (Becton Dickinson). At least 10000 events were counted for each acquisition. Data were analysed using the WinMDI software (version 2.5, Joseph Trotter, Scripps Research Institute, La Jolla, California, USA).

\section{Study of TNF-induced apoptosis in PBMCs}

Apoptosis assays were performed as previously described. ${ }^{18}$ Briefly, freshly isolated PBMCs $\left(1 \times 10^{6}\right)$ were stimulated with $0,1,10$ and $100 \mathrm{ng} / \mathrm{ml} \mathrm{TNF} \alpha$ and cycloheximide $(50 \mu \mathrm{g} / \mathrm{ml}$, Sigma) either alone or in combination for $6 \mathrm{~h}$ at $37^{\circ} \mathrm{C}$. Apoptosis was analysed using FITC-conjugated annexin $\mathrm{V}$ staining (Becton Dickinson) and flow cytometry.

\section{Statistical analysis}

Statistical analyses were performed using the SPSS program, version 12.0. The Kolmogorov-Smirnov test was used to test for normal distribution. Parametric and non-parametric tests, including the Student $t$ test, Mann-Whitney U, Wilcoxon, Kruskal-Wallis and Friedman tests, were used as appropriate. To test for shedding differences between patients and controls, ratios and differences between stimulated and unstimulated cells were calculated to adjust for differences in a priori receptor expression. $p$ Values $<0.05$ were considered significant. 
Table 2 Effect of etanercept treatment on serum acute phase parameters as well as tumour necrosis factor $\alpha$ and interleukin 6 concentrations in V173D mutation-positive family members

\begin{tabular}{lrrr}
\hline & 1-I.2 & 1-II.1 & 1-II.3 \\
\hline CRP (mg/l) & & & \\
Before etanercept & 26 & 121 & 268 \\
Etanercept for 3 months & 10 & 1 & 7 \\
Etanercept for 6 months & 108 & 3.1 & 1 \\
Etanercept for 12 months & 4 & 18.5 & 39 \\
& & & \\
ESR $(\mathrm{mm} / 1 \mathrm{st}$ h) & 60 & 72 & 70 \\
Before etanercept & 16 & 4 & 8 \\
Etanercept for 3 months & 1 & 6 & 10 \\
Etanercept for 6 months & 8 & 8 & 14 \\
Etanercept for 12 months & & &
\end{tabular}

\section{$T N F \propto(p g / m l)$}

Before etanercept

Etanercept for 3 months

Etanercept for 6 months

Etanercept for 12 months

$\begin{array}{rrr}19 & 15 & 64 \\ 251 & 190 & 198 \\ 111 & 86 & 96 \\ 37 & 30 & 36\end{array}$

\section{IL6 (pg/ml)}

Before etanercept

Etanercept for 3 months

Etanercept for 6 months

Etanercept for 12 months

CRP, C-reactive protein (normal $<5 \mathrm{mg} /$ ) ; ESR, erythrocyte sedimentation rate (normal $<10 \mathrm{~mm} / 1 \mathrm{st} \mathrm{h}$ ); IL6, interleukin 6 (normal $<3 \mathrm{pg} / \mathrm{ml}$ ); TNF $\alpha$, tumour necrosis factor $\alpha$ (normal $<20 \mathrm{pg} / \mathrm{ml})$.

\section{RESULTS}

\section{TNFRSF1A mutation detection}

Sequence analysis of exons 2, 3, 4 and 6 of the TNFRSF1A gene in the index patient of family 1 revealed a novel heterozygous GTT to GAT transversion in exon 6, resulting in a valine-toasparagine substitution at residue 173 (V173D/p.Val202Asp) (fig 1A). This amino acid exchange directly affects the major receptor cleavage site, which is located between p.Asn201 and p.Val202. This mutation was present in all family members except the healthy father and one healthy sister (fig 1B) and was not detected in more than 2000 control chromosomes. Three additional TNFRSF1A mutation-positive families were included, of which family 2 demonstrated heterozygosity for c.19414G $>$ A, a known TNFRSF1A splice site mutation, while families 3 and 4 were positive for the low-penetrance TNFRSF1A mutation R92O (fig 1B).

\section{The V173D mutation is associated with TRAPS: typical clinical features, atypical complications and sustained clinical response to etanercept}

Table 1 summarises the main clinical signs/symptoms and laboratory findings of the 11 TNFRSF1A mutation-positive subjects.

The male:female ratio was 6:5. Most of the TRAPS characteristic features were associated with the fully penetrant V173D substitution in family 1. Cardiovascular complications developed in two affected family 1 members. After a severe gastroenteritis, the V173D-heterozygous sister (1-II.2) of the index patient (1-II.1) died at the age of 22 years owing to heart failure associated with myocardial infarction with subsequent ventricular thrombosis and A cerebri media infarction. Serological antibody screening for viruses was negative. At the age of 21 years, her brother (1-II.3) developed an arterial thrombosis of the left A poplitea owing to cystic degeneration of the intima, warranting local desobliteration with thrombectomy and subsequent oral anticoagulation. None of the affected patients were active smokers. A thorough analysis of the coagulation system (including screening for known hereditary coagulopathies) in all members of family 1 did not show any anomalies at five consecutive clinical visits, except for highly increased fibrinogen concentrations in all TNFRSF1A mutationpositive family members. Repeated assessments of antiphospholipid antibodies, including anticardiolipin and $\beta_{2}$-microglobulin antibodies as well as lupus anticoagulant, also yielded negative results.

All affected family 1 members were initially treated with various non-steroidal anti-inflammatory drugs and cumulative doses of glucocorticosteroids. However, reduction of the intensity of disease-associated symptoms was limited. In contrast, all clinically affected patients of families 2-4 responded to steroid treatment with shortening of the fever episodes or rapid cessation of symptoms, or both.

After diagnosis of TRAPS, TNF $\alpha$-blocking treatment with $25 \mathrm{mg}$ etanercept (Enbrel; Wyeth, Philadelphia, USA) twice weekly was started in all affected family 1 members. All three patients (patient 1-II.2 had already died) showed an immediate response and remained symptom-free with etanercept treatment until the end of follow-up after 18 months. Table 2 shows the measurements of acute phase reactants and proinflammatory cytokines before and after etanercept treatment.

\section{Normal serum levels of sTNFRSF1A and sTNFRSF1B in patients with TRAPS}

Median serum concentrations of sTNFRSF1A and sTNFRSF1B were $1.8 \mathrm{ng} / \mathrm{ml}$ (range 0.92-3.0) and $5.52 \mathrm{ng} / \mathrm{ml}(0.92-36.6)$ in HC. sTNFRSF1A and sTNFRSF1B levels of patients affected by the V173D (sTNFRSF1A median $1.8 \mathrm{ng} / \mathrm{ml}$, range $1.2-2.6$ and sTNFRSF1B median $8.0 \mathrm{ng} / \mathrm{ml}$, range 4.8-13.1), the c.194$14 \mathrm{G}>\mathrm{A}$ and the $\mathrm{R} 92 \mathrm{O}$ mutation did not differ from $\mathrm{HC}$ (fig $2 \mathrm{~A}$ ).

\section{Impaired shedding of TNFRSF1A from stimulated monocytes in patients with the V173D and R920 mutations}

Stimulation with PMA induced shedding of TNFRSF1A from CD14+ monocytes in all TRAPS patients and $\mathrm{HC}$ (figs $2 \mathrm{~B}$ and C). Compared with HC, however, TNFRSF1A shedding was reduced in patients with the V173D (mean (SEM) 86.2 (2.6)\% vs 95.1 (2.4)\%; $<<0.05$ at a dosage of $10 \mathrm{ng} / \mathrm{ml} \mathrm{PMA}$ ) and the R92O substitution, but not in patients with the c.194-14G>A mutation. Levels of sTNFRSF1A in supernatants of PBMCs showed a comparable increase in patients and $\mathrm{HC}$ after stimulation with PMA (fig 2D).

\section{Normal induction of apoptosis in TNF $\alpha$-stimulated PBMCs from patients with the V173D mutation}

To assess whether the V173D mutation is associated with functional alterations other than TNF receptor cleavage, TNF $\alpha$ induced apoptosis was analysed in PBMCs from patients carrying the V173D mutation and from HC. After stimulation of PBMCs with 0,1, 10 and $100 \mathrm{ng} / \mathrm{ml} \mathrm{TNF} \alpha$ in the presence of cycloheximide for $6 \mathrm{~h}$, a similar percentage of cells were annexin $\mathrm{V}$ positive in V173D heterozygotes (mean (SEM) ratio $1 \mathrm{ng} / \mathrm{ml}$ vs unstimulated 17.2 (12.0); vs $10 \mathrm{ng} / \mathrm{ml} 16.2$ (12.0) and vs $100 \mathrm{ng} / \mathrm{ml} 20.3$ (8.7)) and in HC (11.5 (4.9), 23.2 (5.9) and 22.2 (4.5)), respectively) (fig 3 ). 
A

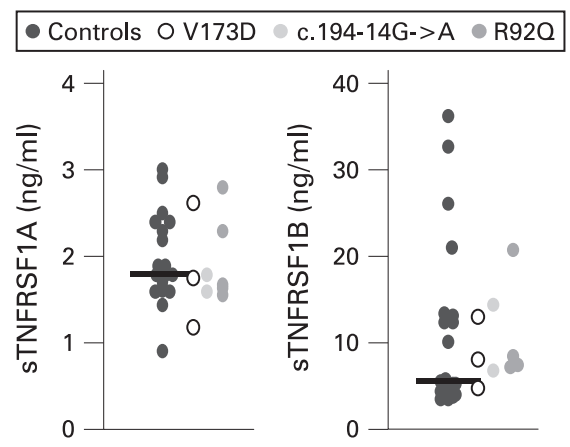

C

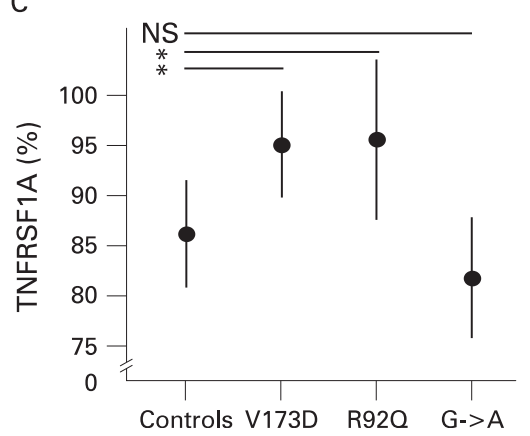

B

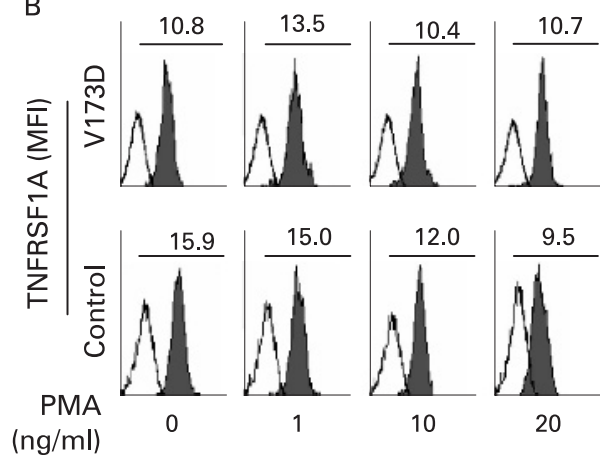

D

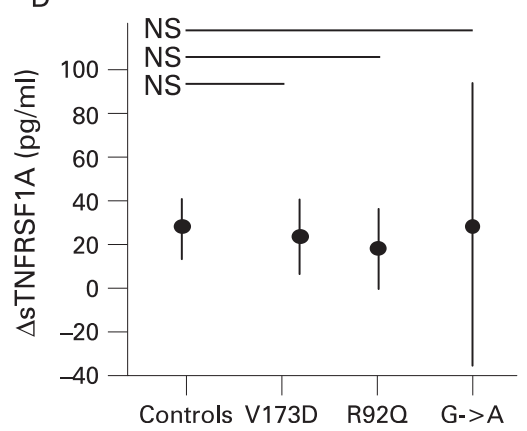

Figure 2 TNFRSF1A shedding in patients with different TNFRSF1A mutations and in healthy controls. (A) Normal levels of soluble TNF receptor superfamily $1 \mathrm{~A}$ (sTNFRSF1A) and 1B (sTNFRSF1B) in patients with the V173D mutation. Levels of sTNFRSF1A and sTNFRSF1B in serum samples from patients with the TNFRSF1A mutations c.605T $>$ AN173D $(n=3), c .194-14 G>A(n=2)$ and c.362G $>A / R 920(n=4)$ and from healthy controls $(n=21)$ were determined by ELISA. Each dot represents the mean of two identical aliquots from a patient, while horizontal lines indicate the median values. $(B, C)$ Impaired shedding of TNFRSF1A from stimulated CD14+ monocytes in patients with the V173D and R920 mutations. (B) Representative histograms show expression of TNFRSF1A (filled curve; the black line represents isotype control) on CD14+ cells from a patient with the V173D mutation and a healthy control without and after stimulation with 1, 10 and $20 \mathrm{ng} / \mathrm{ml}$ phorbol 12 -myristate 13 -acetate (PMA) for $25 \mathrm{~min}$ at $37^{\circ} \mathrm{C}$. MFI, mean fluorescence intensity. (C) Error bars summarise TNFRSF1A shedding from CD14+ cells of healthy controls $(n=26)$ and from patients with the $\operatorname{V173D}(n=3)$, the R920 $(n=4)$ and the $c .194-14 G>A(n=2)$ mutation after stimulation with $10 \mathrm{ng} / \mathrm{ml}$ PMA. Data are shown as the mean $(95 \%$ confidence interval) percentage change (ratio (MFI stimulated/MFI unstimulated cells) $\times 100$ ). (D) Comparable increment of levels of sTNFRSF1A in the supernatant of peripheral blood mononuclear cells from TRAPS patients and healthy controls after stimulation with $10 \mathrm{ng} / \mathrm{ml}$ PMA. Error bars indicate the mean ( $95 \%$ confidence interval) difference of sTNFRSF1A before and after stimulation. ${ }^{*} \mathrm{p}<0.05$ according to the Student $t$ test; NS, not significant.

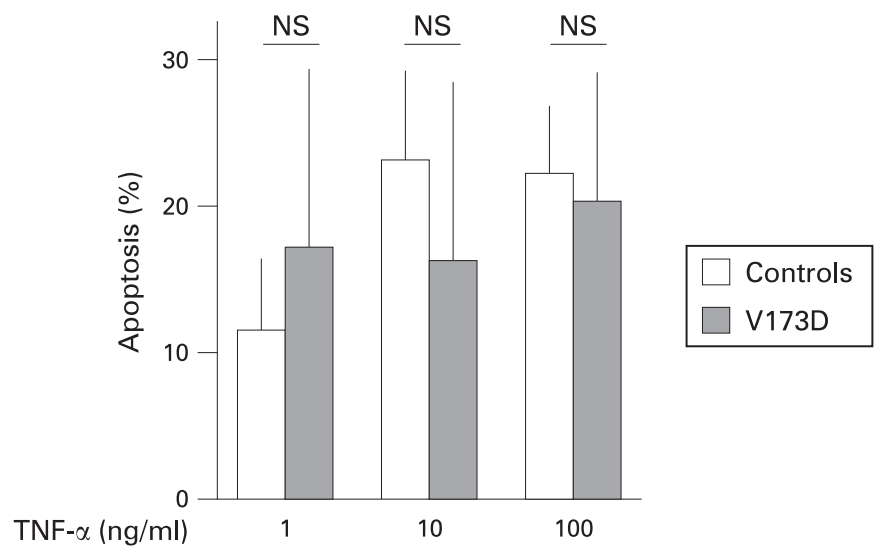

Figure 3 Tumour necrosis factor $\alpha$ (TNF $\alpha$ )-induced apoptosis is not altered in V173D heterozygotes. Freshly isolated peripheral blood mononuclear cells from patients carrying the V173D mutation $(n=3)$ and from healthy controls $(n=6)$ were incubated for $6 \mathrm{~h}$ at $37^{\circ} \mathrm{C}$ with different doses of TNF $\alpha$ in combination with $50 \mu \mathrm{g} / \mathrm{ml}$ cycloheximide as indicated. Boxes indicate the mean (SEM) increase of annexin V-positive cells as a percentage compared with cells incubated with cycloheximide only. Differences were not significant (NS) according to the Student $\mathrm{t}$ test.

\section{Absence of T-cell senescence in patients with the V173D mutation}

Because chronic TNF $\alpha$ receptor signalling is known to induce $T$ cell senescence, ${ }^{24}$ we investigated whether $\mathrm{T}$-cell subsets are altered in patients with the V173D mutation. Table 3 shows that the prevalences of CD4+CD25+ activated $\mathrm{T}$ cells, CD4+CD45RA+ and CD8+CD45RA+ naïve $T$ cells, CD4+CD45RO+ and CD8+CD45RO+ memory $\mathrm{T}$ cells as well as CD4+CD28- and CD8+CD28- memory/effector T cells did not differ from $\mathrm{HC}$ and did not change significantly after TNF $\alpha$ blocking therapy.

\section{DISCUSSION}

The novel TNFRSF1A mutation V173D/p.Val202Asp encoded by exon 6 of the TNFRSF1A gene is unique, since it directly affects the receptor cleavage site, which is located between p.Asn201 and p.Val202. ${ }^{11}{ }^{12}$ All V173D carriers presented with a fully penetrant TRAPS phenotype. Two of them developed cardiovascular complications in addition, leading to the death of one sister due to myocardial infarction and to the development of arterial thrombosis in one brother. None of the mutationpositive family members showed any coagulation abnormality and hyperfibrinogenaemia as the sole cause of these complications seems to be unlikely. 
Table 3 T-cell subtypes in V173D carriers before and after treatment with etanercept compared with healthy controls

\begin{tabular}{lccc}
\hline T-cell subtypes & $\begin{array}{l}\text { V173D - etanercept } \\
(\mathbf{n}=\mathbf{3})\end{array}$ & $\begin{array}{l}\text { V173D + etanercept } \\
(\mathbf{n}=\mathbf{3})\end{array}$ & $\begin{array}{l}\text { Healthy controls } \\
(\mathbf{n}=\mathbf{1 7})\end{array}$ \\
\hline CD4+ T cells & & & \\
Naïve (CD28+CD45RA+) & $67.0(59.3-71.7)$ & $29.0(23.0-32.7)$ & $44.7(27.8-69.3)$ \\
Memory (CD28+CD45R0+) & $41.3(24.1-43.5)$ & $46.8(35.3-52.4)$ & $45.2(30.5-68.1)$ \\
Memory-effector (CD28-) & $0.2(0.1-0.3)$ & $0.7(0.2-0.9)$ & $0.7(0-38.0)$ \\
Activated (CD25+) & $25.0(6.8-32.4)$ & $7.8(6.6-9.6)$ & $12.3(3.0-26.4)$ \\
& & & \\
CD8+ T cells & & & \\
Naïve (CD28+CD45RA+) & $77.8(63.9-90.2)$ & $70.5(42.4-71.8)$ & $45.9(14.5-65.2)$ \\
Memory (CD28+CD45R0+) & $11.0(1.6-40.8)$ & $12.4(6.1-39.4)$ & $19.8(6.3-51.8)$ \\
Memory-effector (CD28-) & $19.2(5.9-25.7)$ & $14.2(1.9-28.2)$ & $21.9(7.6-77.4)$ \\
Activated (CD25+) & ND & $0.9(0.8-1.0)$ & $2.7(0.4-10.5)$
\end{tabular}

Data are shown as the median (range) percentage of CD4+ and CD8+ T cells, respectively. ND, not done.

An increased risk of atherosclerosis has been suggested for R920 carriers in a large European study of subjects with myocardial infarction. ${ }^{25}$ Furthermore, six R92O carriers with Behçet disease developed extracranial venous thrombosis. ${ }^{26}$ Pericarditis and myocarditis have also been reported in $\mathrm{R}^{2} \mathrm{O}^{7}$ and P46L-another low-penetrance variant-heterozygotes. ${ }^{27}$ To assess a potential association of our novel V173D mutation with atherosclerosis, young patients presenting with cardiovascular disease should be screened for this TNFRSF1A receptor cleavage site mutation.

The V173D/p.Val202Asp mutation may have an atherogenic effect, as TNF $\alpha$ is involved in the development of endothelial dysfunction and atherosclerosis, probably potentiated by the prolonged increase of acute phase parameters. ${ }^{28}$ Another possibility is the development of amyloidosis with subsequent cardiomyopathy. However, except for the deceased patient, who was not examined for amyloidosis post mortem, none of the mutation-positive family members showed any clinical signs of amyloidosis. It has also been suggested that TNFRSF1A mutations interfere with the local antithrombotic effect of TNF $\alpha$ during inflammation by impairing the endothelial TNF receptor-mediated iNOS stimulation. ${ }^{26} \mathrm{~A}$ link between premature $\mathrm{T}$-cell ageing, early atherosclerotic damage and multivessel coronary artery disease as established for rheumatoid arthritis and unstable angina, ${ }^{29-31}$ on the other hand, seems unlikely for patients carrying TNFRSF1A mutations because concentrations of CD28- T cells as a marker of early $\mathrm{T}$-cell ageing were normal in our V173D patients.

Earlier in vitro experiments had demonstrated that TNFRSF1A shedding is partially impaired when the valine residue at position 202 is substituted by aspartic acid, glycine or arginine, whereas replacement with proline resulted in a marked decrease in shedding. ${ }^{12}$ Accordingly, monocytes from our TRAPS patients with the V173D/p.Val202Asp mutation showed a partially, but significantly reduced shedding compared with HC. Levels of sTNFRSF1A, in contrast, increased to a comparable extent in PBMC supernatants after stimulation. One reason for this discrepancy may be that the sTNFRSF1A concentrations measured by ELISA were near the detection limit of the assay, causing some imprecision. Alternatively, and as already described for other TRAPS mutations, receptor shedding may differ between various cell types. ${ }^{15}$ This hypothesis is corroborated by our results for the R92O and c.19414G $>$ A mutations, which are consistent with previously published data. ${ }^{6}$ Furthermore, our results suggest that the normal receptor protein synthesised from the intact allele compensates in part for the cleavage deficiency, at least in monocytes.

TNF $\alpha$-induced apoptosis of PBMCs in our V173D patients did not differ from that of HC. However, as we did not analyse other cell types such as fibroblasts or neutrophils, for which apoptotic resistance has been described in TRAPS patients carrying cysteine mutations, ${ }^{9}{ }^{18}$ we cannot completely rule out such a defect in our V173D patients. Whether TNFRSF1A cleavage site mutations, including the V173D variant, cause functional impairments in addition to the TNFRSF1A shedding defect awaits further investigations.

Owing to the limited responsiveness of our V173D patients to non-steroidal anti-inflammatory drugs and steroids and the suggested receptor shedding defect, we started anti-TNF $\alpha$ therapy with etanercept. All patients responded with cessation of their clinical symptoms shortly after the start of treatment. The associated sharp rise in TNF $\alpha$ serum levels seen in our patients is consistent with previous findings about the "buffer" function of sTNFRSF1A which can continually release TNF $\alpha$ into the circulation. ${ }^{14}$ Under sustained etanercept treatment, however, the TNF $\alpha$ levels declined and remained only slightly raised in all patients. The effectiveness of etanercept treatment in our patients with an obvious TRAPS phenotype again confirms the results of the in vitro experiments performed earlier by Brakebusch et al. ${ }^{12}$

In summary, we have identified a new TNFRSF1A mutation directly affecting the receptor cleavage site, which is associated with a severe TRAPS phenotype and cardiovascular complications. Despite an associated partial shedding defect, patients had normal serum levels of sTNFRSF1A and TNF $\alpha$, but were highly responsive to etanercept treatment over the course of $1 \frac{1}{2}$ years.

Acknowledgements: We thank all patients and their parents who participated in this study and Dieter Kunz for excellent technical assistance. We also thank P Lohse, $\mathrm{H}$ Ruebsamen and G Simon (Department of Clinical Chemistry - Grosshadern) for their help in performing the DNA sequence analyses.

Funding: This work was supported by the Verein zur Förderung der Hämatologie, Onkologie und Immunologie and the Verein zur Förderung der wissenschaftlichen Ausbildung und Tätigkeit an der Universität Innsbruck, Innsbruck, Austria.

Competing interests: None

Ethics approval: The study was approved by the ethics committee of the Innsbruck Medical University, Austria. 


\section{REFERENCES}

1. Stojanov S, Kastner DL. Familial autoinflammatory diseases: genetics, pathogenesis and treatment. Curr Opin Rheumatol 2005;17:586-99.

2. McDermott MF, Aksentijevich I, Galon J, McDermott EM, Ogunkolade BW, Centola $\mathrm{M}$, et al. Germline mutations in the extracellular domains of the $55 \mathrm{kDa}$ TNF receptor, TNFR1, define a family of dominantly inherited autoinflammatory syndromes. Cell 1999;97:133-44.

3. Hull KM, Drewe E, Aksentijevich I, Singh HK, Wong K, McDermott EM, et al. The TNF receptor-associated periodic syndrome (TRAPS). Emerging concepts of an autoinflammatory disorder. Medicine (Baltimore) 2002;81:349-68.

4. Stojanov S, McDermott MF. The tumour necrosis factor receptor-associated periodic syndrome: current concepts. Expert Rev Mol Med 2005;7:1-18.

5. Touitou I, Lesage S, McDermott M, Cuisset L, Hoffman H, Dode C, et al. Infevers: an evolving mutation database for auto-inflammatory syndromes. Hum Mutat 2004;24:194-8.

6. Aksentijevich I, Galon J, Soares M, Mansfield E, Hull K, Oh HH, et al. The tumornecrosis-factor receptor-associated periodic syndrome: new mutations in TNFRSF1A, ancestral origins, genotype-phenotype studies, and evidence for further genetic heterogeneity of periodic fevers. Am J Hum Genet 2001;69:301-14.

7. Dode C, Andre M, Bienvenu T, Hausfater P, Pecheux C, Bienvenu J, et al. The enlarging clinical, genetic, and population spectrum of tumor necrosis factor receptorassociated periodic syndrome. Arthritis Rheum 2002;46:2181-8.

8. Aganna E, Hammond L, Hawkins PN, Aldea A, McKee SA, van Amstel HK, et al. Heterogeneity among patients with tumor necrosis factor receptor-associated periodic syndrome phenotypes. Arthritis Rheum 2003;48:2632-44.

9. D'Osualdo A, Ferlito F, Prigione I, Obici L, Meini A, Zulian F, et al. Neutrophils from patients with TNFRSF1A mutations display resistance to tumor necrosis factorinduced apoptosis. Arthritis Rheum 2006;54:998-1008.

10. Kriegel MA, Huffmeier U, Scherb E, Scheidig C, Geiler T, Kalden JR, et al. Tumor necrosis factor receptor-associated periodic syndrome characterized by a mutation affecting the cleavage site of the receptor: implications for pathogenesis. Arthritis Rheum 2003:48:2386-8.

11. Gullberg U, Lantz M, Lindvall L, Olsson I, Himmler A. Involvement of an Asn/Val cleavage site in the production of a soluble form of a human tumor necrosis factor (TNF) receptor. Site-directed mutagenesis of a putative cleavage site in the p55 TNF receptor chain. Eur J Cell Biol 1992;58:307-12.

12. Brakebusch C, Varfolomeev E, Batkin M, Wallach D. Structural requirements for inducible shedding of the p55 tumor necrosis factor receptor. J Biol Chem 1994;269:32488-96.

13. McDermott EM, Powell RJ. Circulating cytokine concentrations in familial Hibernian fever. In: Sohar E, Gafni M, Pras J, eds. Familial mediterranean fever. London and Tel Aviv: Freund Publishing House, 1997:189-92.

14. Nowlan ML, Drewe E, Bulsara H, Esposito N, Robins RA, Tighe PJ, et al. Systemic cytokine levels and the effect of etanercept in TNF receptor-associated periodic syndrome (TRAPS) involving a C33Y mutation in TNFRSF1A. Rheumatology (Oxford) 2006; 45:31-7.

15. Huggins ML, Radford PM, Mclntosh RS, Bainbridge SE, Dickinson P, Draper-Morgan $\mathrm{KA}$, et al. Shedding of mutant tumor necrosis factor receptor superfamily $1 \mathrm{~A}$ associated with tumor necrosis factor receptor-associated periodic syndrome: differences between cell types. Arthritis Rheum 2004;50:2651-9.

16. Yousaf N, Gould DJ, Aganna E, Hammond L, Mirakian RM, Turner MD, et al. Tumor necrosis factor receptor I from periodic syndrome patients interact with wild-type TNFR1 inducing TNF-independent NF-кB activation. Arthritis Rheum 2005;52:2906-16.
17. Todd I, Radford PM, Draper-Morgan KA, Mclntosh R, Bainbridge S, Dickinson P, et al. Mutant forms of tumour necrosis factor receptor I that occur in TNF-receptorassociated periodic syndrome retain signalling functions but show abnormal behaviour. Immunology 2004;113:65-79.

18. Siebert S, Amos N, Fielding CA, Wang EC, Aksentijevich I, Williams BD, et al. Reduced tumor necrosis factor signaling in primary human fibroblasts containing a tumor necrosis factor receptor superfamily $1 \mathrm{~A}$ mutant. Arthritis Rheum 2005; 52:1287-92.

19. Lobito AA, Kimberley FC, Muppidi JR, Komarow H, Jackson AJ, Hull KM, et al. Abnormal disulfide-linked oligomerization results in ER retention and altered signaling by TNFR1 mutants in the TNFR1 associated periodic fever syndrome (TRAPS). Blood 2006;108:1320-7.

20. Stojanov S, Lohse P, Lohse P, Hoffmann F, Renner ED, Zellerer S, et al. Molecular analysis of the MVK and TNFRSF1A genes in patients with a clinical presentation typical of the hyperimmunoglobulinemia $D$ with periodic fever syndrome: a lowpenetrance TNFRSF1A variant in a heterozygous MVK carrier possibly influences the phenotype of hyperimmunoglobulinemia $D$ with periodic fever syndrome or vice versa. Arthritis Rheum 2004;50:1951-8.

21. Stojanov S, Weiss M, Lohse P, Belohradsky BH. A novel CIAS1 mutation and plasma/cerebrospinal fluid cytokine profile in a German patient with neonatal-onset multisystem inflammatory disease responsive to methotrexate therapy. Pediatrics 2004;114:e124-7.

22. Duftner C, Seiler R, Klein-Weigel P, Göbel H, Goldberger C, Ihling C, et al. High prevalence of circulating CD4+CD28- T-cells in patients with small abdominal aortic aneurysms. Arterioscler Thromb Vasc Biol 2005;25:1347-52.

23. Nevala H, Karenko L, Stjernberg S, Raatikainen M, Suomalainen H, Lagerstedt A, et al. A novel mutation in the third extracellular domain of the tumor necrosis factor receptor 1 in a Finnish family with autosomal-dominant recurrent fever. Arthritis Rheum 2002;46:1061-6.

24. Bryl E, Vallejo AN, Weyand CM, Goronzy JJ. Down-regulation of CD28 expression by TNF- $\alpha$. J Immunol 2001;167:3213-38.

25. Poirier 0, Nicaud V, Gariepy J, Courbon D, Elbaz A, Morrison C, et al. Polymorphism $\mathrm{R} 920$ of the tumour necrosis factor receptor 1 gene is associated with myocardial infarction and carotid intima-media thickness - the ECTIM, AXA, EVA and GENIC Studies. Eur J Hum Genet 2004;12:213-9.

26. Amoura Z, Dode C, Hue S, Caillat-Zucman S, Bahram S, Delpech M, et al. Association of the R920 TNFRSF1A mutation and extracranial deep vein thrombosis in patients with Behçet's disease. Arthritis Rheum 2005;52:608-11.

27. Trost S, Rose CD. Myocarditis and sacroilitis: 2 previously unrecognized manifestations of tumor necrosis factor receptor associated periodic syndrome. $J$ Rheumatol 2005;32:175-7.

28. Chia S, Qadan M, Newton R, Ludlam CA, Fox KA, Newby DE. Intra-arterial tumor necrosis factor-alpha impairs endothelium-dependent vasodilatation and stimulates local tissue plasminogen activator release in humans. Arterioscler Thromb Vasc Biol 2003;23:695-701.

29. Liuzzo G, Goronzy JJ, Yang H, Kopecky SL, Holmes DR, Frye RL, et al. Monoclonal Tcell proliferation and plaque instability in acute coronary syndromes. Circulation 2000;101:2883-8.

30. Gerli R, Schillaci G, Giordano A, Bocci EB, Bistoni O, Vaudo G, et al. CD4+CD28- T lymphocytes contribute to early atherosclerotic damage in rheumatoid arthritis patients. Circulation 2004;109:2744-8.

31. Warrington KJ, Kent PD, Frye RL, Lymp JF, Kopecky SL, Goronzy JJ, et al. Rheumatoid arthritis is an independent risk factor for multi-vessel coronary artery disease: a case control study. Arthritis Res Ther 2005;7:R984-91.

\section{Stay a step ahead with Online First}

We publish all our original articles online before they appear in a print issue. This means that the latest clinical research papers go straight from acceptance to your browser, keeping you at the cutting edge of medicine. We update the site weekly so that it remains as topical as possible. Follow the Online First link on the home page and read the latest research. 


\section{ARD}

\section{Clinical and functional characterisation of a novel TNFRSF1A c.605T>A/V173D cleavage site mutation associated with tumour necrosis factor receptor-associated periodic fever syndrome (TRAPS), cardiovascular complications and excellent response to etanercept treatment}

S Stojanov, C Dejaco, P Lohse, et al.

Ann Rheum Dis 2008 67: 1292-1298 originally published online January 7, 2008

doi: 10.1136/ard.2007.079376

Updated information and services can be found at:

http://ard.bmj.com/content/67/9/1292.full.html

These include:

References This article cites 30 articles, 8 of which can be accessed free at: http://ard.bmj.com/content/67/9/1292.full.html\#ref-list-1

Article cited in:

http://ard.bmj.com/content/67/9/1292.full.html\#related-urls

Email alerting Receive free email alerts when new articles cite this article. Sign up in service the box at the top right corner of the online article.

Topic Articles on similar topics can be found in the following collections

Collections

Immunology (including allergy) (3759 articles)

Genetics (720 articles)

Notes

To request permissions go to:

http://group.bmj.com/group/rights-licensing/permissions

To order reprints go to:

http://journals.bmj.com/cgi/reprintform

To subscribe to BMJ go to:

http://group.bmj.com/subscribe/ 